\title{
Allergic Reaction Following Implantation of a Blood Glucose Sensor
}

\begin{tabular}{|c|c|c|}
\hline Author(s) & \multicolumn{2}{|c|}{ (D) Müge Atar, (D) Özgür Pirgon, (D) Gülsüm Çetin } \\
\hline Affiliation(s) & \multicolumn{2}{|c|}{$\begin{array}{l}\text { Süleyman Demirel University, Faculty of Medicine, Department of Pediatric Endocrinology and Diabetes, } \\
\text { Isparta, Turkey }\end{array}$} \\
\hline \multirow{3}{*}{$\begin{array}{c}\text { Article } \\
\text { Information }\end{array}$} & Article Type: Case Report & Received: 26.10 .2021 \\
\hline & Article Group: Pediatric Endocrinology & Accepted: 22.12 .2021 \\
\hline & & Available Online: 31.12 .2021 \\
\hline
\end{tabular}

Cite this article as: Atar M, Pirgon Ö, Çetin G. Allergic Reaction Following Implantation of a Blood Glucose Sensor. J Pediatr Acad 2021; 3: 121-122.

Increasing incidence and onset at a younger age has changed the treatment strategy of diabetes mellitus (DM) towards prevention, delaying the onset, and minimizing disease complications. Self-monitoring blood glucose systems and continuous glucose monitoring systems are routinely preferred in diabetic children. ${ }^{1}$ The FreeStyle ${ }^{\circledR}$ Libre $^{\mathrm{TM}}$ Flash glucose monitoring system (Abbott Diabetes Care, Alameda, CA) has come as an entirely new concept in glucose monitoring by providing much greater data than blood glucose testing while being more affordable than the continuous glucose monitors. The FreeStyle Libre provides 'flash glucose monitoring' with glucose readings by scanning a sensor rather than pricking the patient's finger. The sensor measures interstitial tissue glucose levels every minute via a disposable round sensor with a small catheter inserted under the skin that can be worn for up to 14 days. The entire system's on-body sensor patch worn on the back of the upper arm is disposable. However, the mild erythema may occur on the skin and disappear spontaneously after 24 hours from the detachment of the sensor. Similar skin lesions were observed in diabetic patients, and there was moderate to severe itching in $0.5 \%$ of the cases and moderate erythema in $4 \%$ of cases. ${ }^{2}$

Our patient, a seven-year-old boy, was followed with the diagnosis of type 1 diabetes since six years old, and he was started to check his blood glucose levels via The FreeStyle
Libre 10 days ago. However, he developed severe pruritis after implantation. After removing the sensor, skin irritation and a local cutaneous reaction, probably allergic reaction to the sensor containing the latex was detected. The patient did not report a history of allergy to medications or adhesive tapes. The sensor patch was removed, and dermatitis was resolved by the application of topical creams containing corticosteroids (Figure 1)

Although there is not enough experience in children, the FreeStyle Libre is often preferred by parents because of the lack of fingerstick measurement and the ability to check glucose levels frequently. We thought that allergic reactions would also be seen more frequently depending on the increase in the frequency of use. Application of topical products such as a blood glucose sensor can potentiate local or systemic hypersensitivity reactions. Because The FreeStyle Libre system is accessible for home use, health care providers need to be aware of its potential consequences.

The continuous glucose monitoring systems improves the quality of diabetic patients life and relieves them the burden of repeatedly measuring blood glucose. Local steroids generally recommended in reactions such as dermatitis. Additionally, there are alternative products that can be used for a period of 3-15 days. 


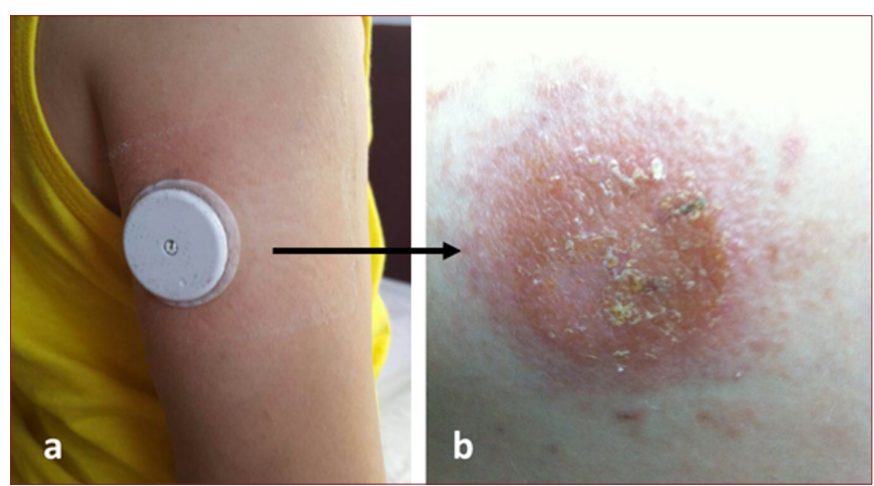

Figure 1. Allergic skin reaction was detected after the removal of the patch

Keywords: Flash glucose monitoring, type 1 diabetes, dermatitis

Author Contributions: All of the authors declare that they have all participated in the design, execution, and analysis of the paper, and that they have approved the final version.
Conflict of Interest: The authors have no conflict of interest to declare.

Financial Disclosure: The authors declared that this study has received no financial support.

Informed Consent: Written informed consent was obtained from patients who participated in this study.

Peer-review: Externally peer-reviewed.

\section{References}

1. Bahíllo-Curieses MP, Díaz-Soto G, Vidueira-Martínez AM, Torres-Ballester I, Gómez-Hoyos E, de Luis-Román D. Assessment of metabolic control and use of flash glucose monitoring systems in a cohort of pediatric, adolescents, and adults patients with Type 1 diabetes. Endocrine. 2021;73:47-51. [CrossRef]

2. Bailey T, Bode BW, Christiansen MP, Klaff LJ, Alva S. The Performance and Usability of a Factory-Calibrated Flash Glucose Monitoring System. Diabetes Technol Ther. 2015;17:787-94. [CrossRef] 